\title{
Four-in-Five Adults Are Vaccinated or Intend to Get a Vaccine
}

Sarah Boege

$\mathrm{B}$ y March 29, one-quarter of U.S. adults reported that they had already received at least one dose of a COVID-19 vaccine. In addition, 39.1 percent hadn't yet been vaccinated but reported that they will "definitely" get one when available and another 17.4 percent said that they "probably" will. In total, 80.9 percent of U.S. adults reported that they either had already received a COVID-19 vaccine or intend to get a vaccine. However, 10.1 percent of adults will "probably not" and 8.2 percent will "definitely not" get a vaccine. The share of adults in each state who have either been vaccinated or intend to get a vaccine varies considerably, from 66.3 percent in Wyoming to 89.1 percent in Massachusetts (see interactive map). The intentions of those not yet vaccinated also varies substantially by state. Shares of adults who are not yet vaccinated but will definitely get a vaccine were highest in the regions of New England and the Pacific Coast (highest in Massachusetts at 49.1 percent and lowest in Mississippi at 25.0 percent). These data suggest that a large majority of adults could be vaccinated in the coming months, but experts see risks in having a sizeable group remain unvaccinated. COVID-19 vaccines are also not yet widely available to children and youth under 16 years old.

\section{PERCENT OF ADULTS WHO ARE VACCINATED OR INTEND TO GET A VACCINE BY STATE}

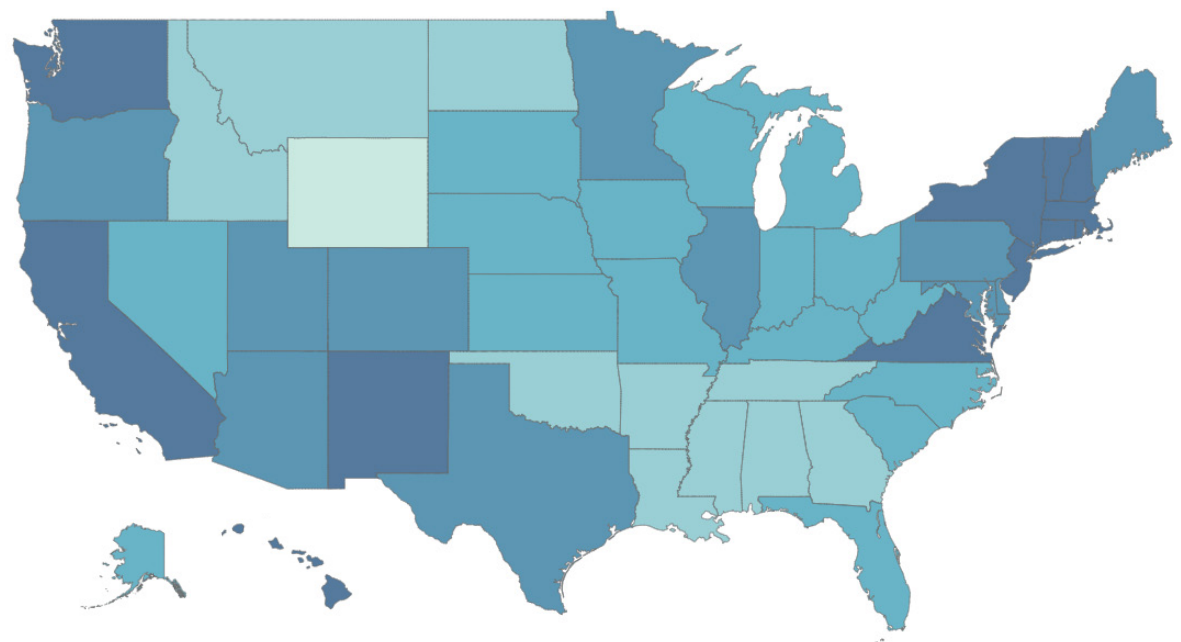

Percent of Adult Population 66.3

Analysis: S. Boege, Carsey School, University of New Hampshire Source: Household Pulse Survey, U.S. Census Bureau, Week 22-Week 27 (January 6-March 29, 2021)

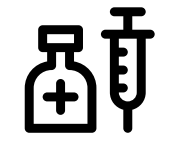

80.9 percent of U.S. adults reported that they either had already received a COVID-19 vaccine or intend to get a vaccine when it becomes available to them.

\section{About the Author \\ Sarah Boege is a policy analyst with both the Vulnerable Families Research Program and the Center for Impact Finance at the Carsey School of Public Policy.}

Notes: Percentages represent the share of adults ages 18 and older in a given state who reported that they either had already received a COVID-19 vaccine or "definitely" or "probably" will get a vaccine when they are eligible. Questions regarding COVID-19 vaccine receipt and vaccination intentions were added during Phase 3 in the version of the Household Pulse Survey Questionnaire that began in the field January 6, 2021 (Week 22). In order to produce more reliable state-level estimates, Weeks 22-27 (spanning January 6-March 29, 2021) of the Household Pulse Survey Public Use Files (PUF) were pooled for this analysis. Since respondents were asked about their personal vaccination status and intentions (rather than about the entire household), this analysis used person weights and replicate weights. 